\title{
A Review Paper on Biodegradable Composites Made from Banana Fibers
}

\author{
Amrinder Singh Pannu ${ }^{1}$, Sehijpal Singh ${ }^{2}$ and Vikas Dhawan ${ }^{3}$ \\ ${ }^{1}$ Research Scholar, Mechanical Engineering Department, IKG-PTU, Kapurthala, Punjab, India, and \\ Assistant Professor, Mechanical Engineering Department, Guru Nanak Dev Engineering College, \\ Ludhiana, Punjab, India \\ ${ }^{2}$ Principal, Guru Nanak Dev Engineering College, Ludhiana, Punjab, India \\ ${ }^{3}$ Director/Principal, Chandigarh Engineering College, Mohali, Punjab, India \\ E-Mail: erpannu85@gmail.com
}

\begin{abstract}
Composites are defined as mixture of two or more ingredients where one is called as matrix (larger in quantity) and other is called reinforcement (smaller in quantity). Now a days research is concentrated towards various methods of making biodegradable composites where either reinforcement or matrix are biodegradable or both are biodegradable. Composites have so many applications in industrial as well as commercial use due to their low weight to strength ratio that attracted the automobile manufacturers to use these materials in cars which in turn increases the efficiency as well as reduce the cost of the automobile. In this paper effort has been made to investigate various process of manufacturing composites manufactured from banana fibers using different matrix preferably PLA (Polylactic Acid). The methods of improving the bonding between the reinforcement and matrix, effect of fiber orientation, size of the fibers and percentage reinforcement has been studied.
\end{abstract}

Keywords: Polylactic Acid (PLA), Banana fibers, Biodegradable composites, reinforcement, Manufacturing, Treatment

\section{INTRODUCTION}

In today's scenario, due to the industrialization, the environmental degradation is attracting the people all over the globe to think about the future material that could be more sustainable and eco-friendly in nature. These biodegradable plastics and other bio based polymers when used as composites can replace the petro based polymers in the market up to the large extent. Composites are classified as non- biodegradable and biodegradable in nature. Biodegradable can be partially or fully depending upon the type of matrix and reinforcement.

\section{A. Introduction to PLA}

Polylactic acid (PLA) belongs to the group family of aliphatic polyesters that are usually made from hydroxy acids that comprises of polyglycolic acid that is mainly considered as biodegradable. PLA are high modulus polymers having high strength and of thermoplastic in nature that are usually derived from renewable resources on the earth for their application in various fields like industrial and medical sciences. Due to their biodegradable nature and common process of extraction and utilization of various biodegradable wastes, its uses are increasing day by day in all the fields of engineering and science. The interest of making PLA arises as it fulfills the needed factors like cost effectiveness and non-petroleum products. PLA is a bioplastic which is very versatile as it degrades when come in contact with environment. One can say that if bottle made of PLA if left in water then it will automatically degrade within maximum 2 years as compare to other conventional plastics that usually take hundreds or even thousands of years to degrade completely. So there has been a high potential for PLA as it is very much useful where biodegradability is highly beneficial specially the product having short life span.

\section{B. Classification of PLA}

Natural fiber reinforced composites are attracting the researchers and end users due to their low cost and improved sustainability which force them to replace the synthetic fiber reinforced composites with natural ones. So there is the need to develop new materials based on renewable resources. So to make completely biodegradable green composites, both matrix and reinforcement should be biodegradable. The classification of natural matrices is given below in figure no 2 :

From the given classification of matrices, at present PLA (Polylactic Acid) is widely used in most of the research works and till date going on. It was discovered by the Carothers by heating up the lactic acid under the vacuum in 1932. The final product has a very low molecular weight. PLA being a versatile, degradable, had displaced polymers based on fossil fuels and also their performance is very good as compare to the other upcoming polymers. At the initial stage of research of biodegradable polymer, PGA (Poly-glycolic acid) was the first to be synthesized followed by PLA (poly-lactic acid) for their use as implant materials for the repair of various types of tissues [2-4]. In further research, the scientists need the product having little high molecular weight which results into synthesis of high molecular weight PLA by the polymerization of lactide by ring opening. In medical field, PLA has been used as a drug delivery matrices and internal fixation of fractured bones [5]. In terms of agriculture, it has been used as growth promoter in plants, textiles and crop covers etc. Now a day's PLA has become an alternative to HIPS, PET, and PVC. This novel matrix has a forging role in containers and thermoformed cups. PLA has glass transition temperature 
ranging from $50-59^{\circ} \mathrm{C}$ and melting point of $159-178^{0} \mathrm{C}$ for its different process grades [6]. The properties of PLA as compare to other polymers in terms of mechanical strength are given in the table no 1 . Due to the awareness and increasing attention towards the development of biodegradable products, the monomers are being manufactured from the various renewable feed stocks which inturn bring the PLA as a emerging solution to the plastic industry worldwide. The better methods of processing and improvement in the intrinsic properties of these polymers have increased the interest of commercial sector to make PLA products.

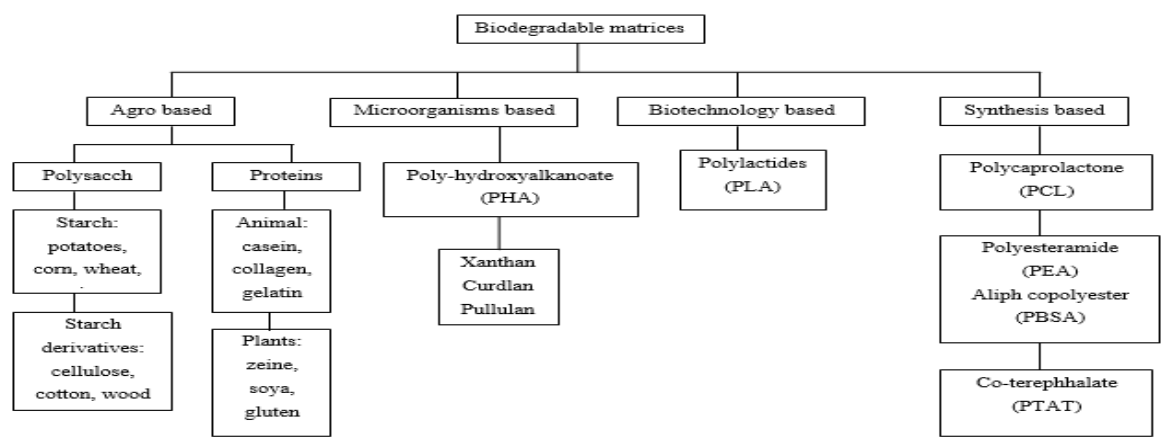

Fig. 1 Classification of Biodegradable polymers (matrices) [1]

TABLE I PROPERTIES OF POLYMERS [7]

\begin{tabular}{|l|c|c|c|c|c|}
\hline \multicolumn{1}{|c|}{ Properties } & PLA & PP & PET & Nylon & Cellophane \\
\hline Density (g/cc) & 1.25 & 0.9 & 1.4 & 1.2 & 1.45 \\
\hline Haze (\%) & 2.1 & $1-4$ & $2-5$ & $2-3$ & $1-2$ \\
\hline Tensile strength (psi) & 15950 & 27550 & 29725 & 36250 & 13050 \\
\hline Tensile modulus (psi) & 478500 & 348000 & 551000 & 264625 & 594500 \\
\hline Ultimate elongation (\%) & 160 & 110 & 140 & 125 & 23 \\
\hline
\end{tabular}

PLA is being processed on a large scale production lines like that of extrusion, blow moulding, injection moulding, thermoforming etc. for which it must possess required stability in thermal to prevent its degradation by maintaining its properties and molecular weight. Its thermal degradation which is generally affected by temperature, time, impurities and catalyst concentration, usually undergoes at temperatures above $200^{\circ} \mathrm{C}$ [8] by various transformations like intera-molecular, hydrolysis, oxidation and lactide reformation. The catalyst used in the PLA increases the degradation rate which inturn affects the mechanical properties and change in viscosity. When we compare the PLA with other biopolymers then one thing has been very cleared that PLA is advantageous due to the factors like use of renewable source (corn) which is produced by fermentation of the lactide monomer which has been produced from the lactic acid and has ability to convert it back into lactic acid by alcoholysis (hydrolysis) which if on one hand improve the economy of the agricultural sector also reduce the land filling on large volumes [9].

\section{Methods of making PLA}

The main source of making PLA is lactic acid (monomer) produced by chemical synthesis or fermentation. Presently two types of configuration of PLA are there named L $(+)$ and D (-) isomers which are produced from the carbohydrates by bacterial fermentation. Out of these above two methods of making PLA, chemical synthesis is not preferred in most of the cases specifically in industries due to the cost of the process and dependency of the process on the other one [10]. So homofermentative method consist of species of Lactobacillus is widely used due the advantages like lesser by products formation and greater lactic acid yielding. Pure L-Lactic acid is used in production of PLA maintaining the $\mathrm{pH}$ (5.6-6.4), temperature $38-42^{\circ} \mathrm{C}$ and low oxygen concentration [11]. There are two main methods of synthesis of PLA from the lactic acid: Low Molecular Weight PLA by Condensation Polymerization and High Molecular Weight PLA by Ring-Opening Polymerization of Lactide.

\section{Applications of PLA}

Due to its biodegradable nature and having good properties, PLA has been widely used in different sectors of engineering industries like packaging (films and trays for biscuits, fruit, vegetables, and meat), agricultural (mulching films), furniture, electrical and electronic appliances (CD's, computer keys, casings etc), houseware and other fibers or fabrics (t-shirts, socks, blankets, wipes, hygiene products, diapers) [12]. The reason is not only that PLA is biodegradable but also due to its performance and properties at a reasonable price. So its use is increasing at a very rapid rate. PLA also proved useful in biomedical science for making various internal components of the body like rods in bones, ankle screws, implants and drug delivery systems [13-15]. 


\section{E. Introduction to Reinforcements}

Reinforcement is defined as an incorporation of a woven or non woven structure of fibrous material which is used to increase the physical properties of the composite that in-turn increase the strength of the neat resin. Different reinforcements have different properties that affect the final properties of the composites. Therefore the selection of reinforcement plays a major role in the making of the composite and its desired properties. Reinforcements could be particles of fabrics, fibers or whiskers. Fibers are characterized as long axis having near circular crosssection. Particles orientation is not fixed in particular direction but on the other hand whiskers have defined shape having very less dimensions (diameter and length) as compare to the fibers. Flakes are used instead of fibers due to their dense packed structure and also they are less costly and can be produced in an economic way.

\section{F. Reinforcements of Natural Fibers}

Artificial fibers like aramid, glass and carbon are being used from a long time but the natural fibers have attracted the researchers due to their availability, less cost etc. due to the low density of these natural fibers (jute, kenaf, flax, sisal etc.), they are highly recommended in automotive industries. Reinforcements again could be biodegradable or non-biodegradable. They may be metallic, wood based, plant and animal based. As our parent requirement is fully biodegradable composite so the biodegradable fibers used as reinforcements are classified as shown in figure 2.

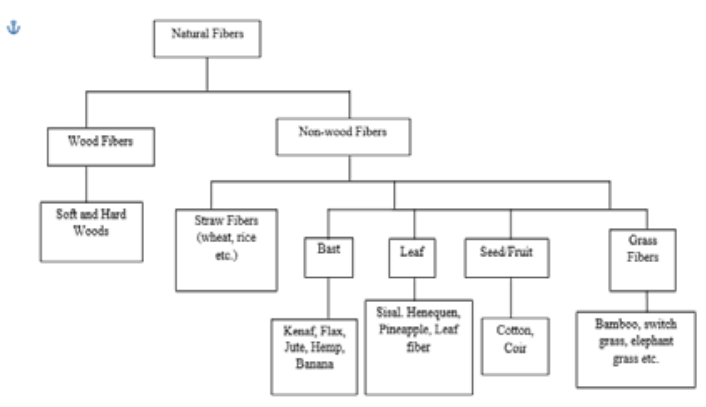

Fig. 2 Classification of natural reinforcements $[16,17]$

\section{G. Treatment of Natural Fibers}

Mostly all the fibers are being used as the reinforcement in the matrix. Reinforcement may be in the form of yarn form, continuous, discontinuous, chopped form etc. The natural fibers extracted from the plants, animals are not being directly used for the purpose of reinforcements as they have impurities and the cellulose etc. which decreases the bonding strength of the fiber with the matrix which inturn affect the properties of the final composite. Lignin, cellulose, waxes, hemi-cellulose are the main components of natural fibers. Some selected fibers' components are given in table no II.

TABLE II CHEMICAL COMPOSITION OF NATURAL FIBERS [16, 17]

\begin{tabular}{|c|c|c|c|c|c|}
\hline Fiber & Lignin (\%) & Cellulose (\%) & Hemi-cellulose (\%) & Pectin (\%) & Ash (\%) \\
\hline Kenaf & $15-19$ & $31-57$ & $21.5-23$ & ---- & $2-5$ \\
\hline Jute & $12-26$ & $45-71.5$ & $13.6-21$ & 0.2 & $0.5-2$ \\
\hline Hemp & $3.7-13$ & $57-77$ & $14-22.4$ & 0.9 & 0.8 \\
\hline Sisal & $7-11$ & $47-78$ & $10-24$ & 10 & $0.6-1$ \\
\hline Abaca & $7-9$ & $56-63$ & $15-17$ & ----- & 3 \\
\hline
\end{tabular}

Cellulose being a semi crystalline polysaccharide comprised of large hydroxyl group which gives hydrophilic properties to natural fibers that result into very poor interface and inturn leads to moisture absorption [18]. Due to the open structure of hemi-cellulose having acetyl and hydroxyl groups, it is hygroscopic and little soluble in water. On the other hand Lignin being amorphous has least water sorption of Natural composites [19]. So to increase the bond strength of the composites, the natural fibers are being chemically treated. So there are various methods of treating these fibers like alkaline treatment, silane treatment, acetylation, benzoylation etc. Alkaline treatment is being commonly used by the researchers when reinforcement is done to either thermoplastics or thermosets. The important function of alkaline treatment is to disrupt the hydrogen bonding in the structure thereby increasing the roughness of the surface of fibers. In this treatment wax, lignin, oils etc covering the outer portion of the fiber has been removed up to certain extent by immersing the fibers into solution of $\mathrm{NaOH}$ for the required period of time which in turn increase the strength of the fibers when reinforced into the matrix [2021]. Silane $\left(\mathrm{SiH}_{4}\right)$ makes the glass fibers properly adhere with the polymer matrix which makes the composite stable. It forms the stable covalent bond by reducing the hydroxyl group of cellulose at the interface of fiber and matrix [22]. It was been confirmed that silane treated fibers are much stronger than the alkaline treatment which leads to the higher tensile strength [23]. Acetylation is an etherification process results into plasticization which involves generation of acetic acid as a byproduct that must be removed from fiber to make it hydrophobic [24]. Benzoylation improve the interaction with hydrophobic by treating the fibers with the benzoyl chloride [25]. Benzoylation improves adhesion of fiber and matrix that increase the strength of the composite by decreasing the water content and improving the thermal stability of the fiber in the matrix. 


\section{METHODS OF MAKING COMPOSITES}

There are different manufacturing techniques of making the composites. Selection of manufacturing technique depends on different factors like availability of fiber form, strength requirement, length of the final product, space available, continuous production and type of product (simple or complicated). For good processing of composite there must exist good bonding between fibers and matrix, proper fiber orientation, fiber volume fraction must be good, uniform distribution of fibers is must, proper curing and solidification and proper curing of resin should be there, lesser defects and voids, and should have good control over the dimensions of the final product. Following are some of the techniques that are being used for manufacturing of composites: Hand layup method, Autoclave moulding, Compression moulding, Injection moulding, Extrusion process, Pultrusion process and Filament winding. As all the above methods have its own advantages and disadvantages depending upon the type of reinforcement and properties of the matrix. The injection molding and hand layup method has been widely used by the researchers to make different types of composites. In injection moulding one can use the chopped form of fibers and in hand layup method both chopped as well as continuous and discontinuous fibers can be used as the reinforcement which make the hand layup method very easy to use with lesser technical skills and is one of the most economic process of making composites. In this research work our aim is to make the green composite with the use of extrusion process so let it be limited to explanation of extrusion process for manufacturing composites.

\section{A. Extrusion process}

Extrusion process has been used to mix up the required ratio of fibers and matrix with the use of heat and forward rotating screw. Extrusion process is of two types: single screw extruder and twin screw extruder as shown in figure 3(a) and 3(b) respectively. Single screw extruder comprised of single screw rotating inside the periphery of barrel where barrel are covered up by the heaters to set the temperature range accordingly. The screw inside the extruder barrel is rotated at the predetermined speed with the help of motor that is a drive unit and die has been attached at the end of the barrel from where material has been pushed to the required shape as that of the die. A control unit has been attached in order to maintain the speed of the screw, temperatures of the barrels and pressure requirements [2627].

The L/D ratio (length diameter ratios) is also one important factor for the selection of single and twin screw extruder that ranges from 20 to $40: 1$ in mm. Single-screw extruder have 3 zones namely: feed zone, compression zone and a metering zone. Twin screw extruder has more mixing capability than a single screw extrusion which make the twin screw extruder more advantageous than single screw extruder in most of the pharmaceutical manufacturing techniques.

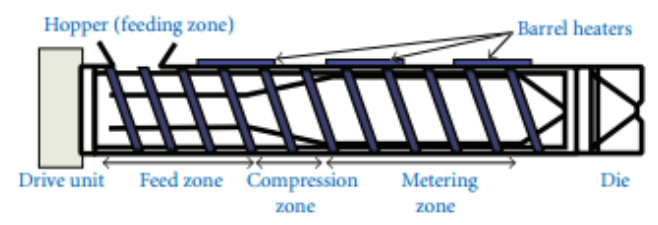

Fig. 3 Schematic diagram of single screw

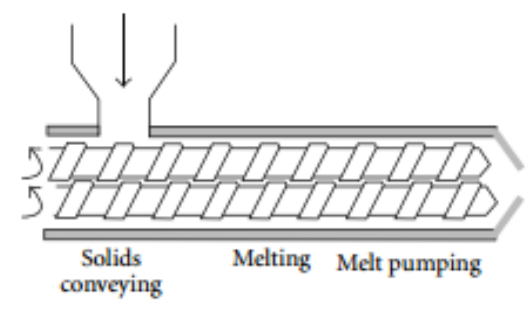

Fig. 4 and twin screw extruder [28-29]

\section{LITERATURE ON BANANA FIBER REINFORCEMENTS}

Santhosh J et.al [30] compared the treated (5\% sodium hydroxide solution for 1 hour time period) and untreated banana fiber and epoxy/vinyl ester reinforced composites. Process used was hand layup method. Volume percentage of banana was $30 \%$ by weight and then tensile strength has been calculated by UTM along with impact and flexural strength. Tensile strength of banana-epoxy composite comes out to be 6.185 and $22.63 \mathrm{MPa}$ and with vinyl ester reading was 11.41 and 17.65 respectively, Flexural strength 24.61 $\mathrm{MPa}$ and 51.28 MPa for epoxy and 33.84 MPa and 48.205 MPa for vinyl ester and for impact strength value comes out to be 4.91 and $8.11 \mathrm{~kJ} / \mathrm{m}^{2}$ in case of epoxy and 2.51 and $3.41 \mathrm{~kJ} / \mathrm{m}^{2}$ with vinyl ester for untreated and treated fibers respectively.

J Madhukiran et. al. [31] investigated the mechanical properties (tensile and hardness) of composites comprised of banana and pineapple as the natural fibers reinforced into epoxy resin. Weight fraction (banana/pineapple) of $0 / 40$, $15 / 25,20 / 20,25 / 15$ and $40 / 0$ was maintained to make the hybrid composite. Results showed that tensile strength increases up to certain extent of weight fraction of fibers i.e. 7.4 MPa to 20.7 MPa with 40/0 and 0/40 weight fraction. With 25/15 ratio it gave tensile strength of $19.6 \mathrm{MPa}$. Hybridization also increased the tensile strength of the composite as compare to the individual reinforcement of the fibres.

Shih Y F and Huang C C [32] prepared composite by melt blending method comprised of polylactic acid (PLA) and banana fiber (BF). Due to the incorporation of banana fibers into PLA, the mechanical and thermal properties increased. The tensile (78.6 MPa) and flexural strength (65.4 MPa) of the composites increased 2 and 1.66 times respectively with 
$40 \%$ reinforcement of fibres when compare with virgin PLA. But on the contrary impact strength reduces with increase in fiber content. Also HDT of virgin PLA increased from $62{ }^{\circ} \mathrm{C}$ to $139{ }^{\circ} \mathrm{C}$ with $40 \%$ fiber fraction which showed $122 \%$ improvement.

Jandas P J et. al. [33] Bio composite comprised of Poly lactic acid (PLA) and Banana fiber (BF) were made by melt blending process. Thereafter compression molding has been done. Banana fibers were treated with $\mathrm{NaOH}$ solution along with some silanes that enhance the fiber-matrix adhesion. Mechanical testing of composite made by treated fibers showed remarkable increase in the tensile strength (136\%) and impact strength (49\%) when compared with untreated green composite. In DSC and TGA testing, it has been revealed that there is a effective adhesion at fiber and matrix interface due to the increase in the melting transitions. With DMA testing it has been concluded that storage modulus increased in silane treated biocomposite.

Paul Sherely Annie et. al. [34] estimated the thermal diffusivity, thermal conductivity, and specific heat of banana fiber reinforced polypropylene (PP) composite. It has been found that with the increase in the fiber loading, the thermal diffusivity and thermal conductivity decreases. But on the contrary specific heat of the composite has no effect of fiber loading in the composite. With the treatment of benzoyl, the fiber reinforced composite shoes high thermal conductivity as well as diffusivity. Also banana fibers treated in $10 \% \mathrm{NaOH}$ solution gave better thermophysical properties as compare to $2 \%$ solution.

Ranjan Ravi et. al. [35] tested the hybrid composite made of banana/sisal (treated and untreated) reinforced in PLA as matrix. In this paper, banana and sisal fibers were selected to execute the hybrid bio-composite preparation with poly lactic as its matrix. Mechanical properties like flexural, tensile and impact were calculated according to ASTM standards. The results showed treated fibers have tensile strength of around $50 \mathrm{MPa}$ as the untreated has around 40 $\mathrm{MPa}$, impact strength of $90 \mathrm{~kJ} / \mathrm{m}^{2}$ and $80 \mathrm{~kJ} / \mathrm{m}^{2}$ with treated and untreated fibers respectively. Flexural strength comes out to be $70 \mathrm{MPa}$ and MPa respectively. The SEM analysis showed good adhesion at the fiber matrix interface. Kumar Rakesh et. al. [36] used a waste product of banana cultivation and reinforced it into soy protein. By using glycerol as a plasticizer (25-50\%), different fractions of volume of alkali treated and untreated banana fibers has been reinforced to make composite. It has been concluded that tensile strength and the modulus of fibers jumped to $292 \mathrm{MPa}$ from $270 \mathrm{MPa}$ and 13696 from $10855 \mathrm{MPa}$, respectively, when treated with $10 \% \mathrm{NaOH}$ solution with volume fraction of 0.3 . Also glutaraldehyde increased the water resistance capacity of the composite.

Deepa B. et. al. [37] extracted cellulose nanofibers from fibers of banana with the help of steam explosion method. During chemical characterization it has been concluded that content of cellulose go up to $95 \%$ from previous figure of
64\% when alkali treatment and acid treatment has been done. Lignin and hemicelluloes produced during acidic treatment and steam explosion were confirmed to be removed with the chemical treatment. Reduction in diameter of fibers has been occurred during the acidic treatment and steam explosion that has been revealed by SEM analysis. Aspect ratio and percentage yield of these nano banana fiber made by steam explosion is found to be high as compare to other available conventional methods. DSC and TGA analysis proved that Steam exploded fibers had good thermal properties as compare to the untreated fibers.

Idicula Maries et. al. [38] investigated the hybrid composite made of randomly oriented sisal and banana fibers with volume fraction of $40 \%$. Tensile strength (55 MPa), flexural strength(73 MPa) and flexural modulus (3926 MPa) showed positive effect of hybridization with varying volume fraction where tensile strength was maximum at fibers ratio of 4:1 (banana: sisal) showing banana being the best having good properties as compare to sisal alone. On the other hand with the increase in volume fraction of sisal, the impact strength increases contrary to hybridized composite. Highest flexural strength (73 $\mathrm{MPa}$ ) has been observed at bilayer type of composite. Banana when used as a skin material and sisal being a core material, tensile properties were higher when compared with other composites.

Thiruchitrambalam. M et. al., [39] investigated the effect of alkaline $(10 \% \mathrm{NaOH})$ and sodium lauryl sulphate $(10 \%)$ on hybrized composite made form treatment of kenaf/banana fiber for 10 minutes and also on woven hybrid composite. Moulding technique has been used. $40 \%$ fiber content is considered. Tensile strength increased by $13 \%$ and $10 \%$ i.e. $50 \mathrm{MPa}$ and $55 \mathrm{MPa}$ for banana/kenaf non woven and woven hybrid composite respectively as compare to non treated fibers. Similarly flexural strength by $12 \%(61 \mathrm{MPa})$, $10 \%(68 \mathrm{MPa})$ and impact strength by $23 \%\left(16 \mathrm{~kJ} / \mathrm{m}^{2}\right), 6 \%$ $\left(21 \mathrm{~kJ} / \mathrm{m}^{2}\right)$ respectively. $\mathrm{NaOH}$ treatment showed good properties as compare to SLS treatment.

Sajna V P et. al. [40] Green nano-composites comprised of untreated and chemically treated (silane treatment, permanganate treatment, mercerization, sodium lauryl sulphate treatment and mercerization-silane treatment) banana fibers and nano clay (Cloisite 30B) mixed with PLA matrix were prepared by injection moulding technique after its melt blending. The composites were mechanically tested along with DSC, TGA HDT and SEM etc. to study the effect of chemical treatment of banana fiber and addition of nano-clay. Reinforcement showed better results in terms of flexural (74-109 MPa), tensile testing (55-72 MPa), storage modulus (bio-nanocomposites) than virgin PLA (58-60 MPa for tensile strength and 93-95 MPa for flexural strength) for different fiber weight fraction with treated and untreated fibers but on the other hand due to brittle nature of PLA, impact testing gave reverse results with the reinforcement (dropped from 202 to $117 \mathrm{~J} / \mathrm{m}$ ). DSC revealed that glass transition remains near to constant but melting temperature 
increased with the incorporation of fiber (silane treated) and nano-clay. TGA showed improvement in degradation temperature with reinforcement. SEM demonstrated proper dispersion of treated fibers in the composites.

Ghosh Rajesh et. al., [41] studied the effect of ultrasonic treatment on mechanical and water absorption properties on composites based on $\mathrm{NaOH}$ treated woven fibers of banana. Tensile strength comes out to be around 122 MPa (4.52\% increase over specimens prepared by the normal process) and flexural strength around $136 \mathrm{MPa}$ (6.21 \% increase over specimens prepared by the normal process) for sonicated dry specimen. Fickian diffusion process has been followed at initial stages thereafter follows Non-Fickian diffusion process. Absorption deteriorates the mechanical properties of the composite. Micro gaps and fiber pull out was there in normally processed specimens as compare to sonicated specimens. Deka Binapani et. al. [42] conducted training of rural women of Romai area of district Dibrugarh for banana fiber extraction process and preparation of various decorative items to aware the people about various extraction process of banana fibers and in-turn complete utilization of banana plants could be there. Pre-test and post-test was done on 25 women that showed significant difference among them. Pre-test showed that $92 \%$ respondent having very less knowledge about extraction process and after test $88 \%$ showed great knowledge about banana utilization and $72 \%$ exhibited very good knowledge regarding the banana fiber extraction techniques. The post evaluation study conducted on adoption of banana fibre extraction showed that out of all the trainees, 20 per cent rural women have already started the techniques of extraction of banana fibre as a household business.

Santhanam V. et. al. [43] used the hand layup method to make composite made form glass and banana fiber (chopped form) reinforced with polyester. Experiments were conducted to find out the effect of volume fraction of fiber in the composites for fraction toughness of mode I of both GFRP and BFRP. Volume percentage of fiber has been taken as $0.13,0.17$ and 0.20 . Fracture toughness comes out to be very close to in both glass fiber and banana fiber reinforced composites i.e. 6.8 and 5.53 and load being 25.6 and 22.4 N respectively. Khalifa Mohammad and Altaf Bagawan [44] mechanically tested the hybrid composites comprised of Jute/banana fibers in yarn form (1, 2 and 3 $\mathrm{mm}$ diameter) reinforced in epoxy matrix. With the increase in volume fraction of fibers, tensile strength increases (33 $\mathrm{MPa}$ for 3mm fiber diameter in hybrid composite). Elongation comes out to be 14 5, 9\% and $8.5 \%$ when loaded along the orientation of fibers and $10 \%, 7.5 \%$ and $6.7 \%$, when loaded perpendicular to fiber orientation for jute, banana and hybrid composite respectively. Stress when loaded along orientation was maximum and minimum when load is perpendicular to orientation. Hybrid composite's tensile strength comes out to be more i.e. increase of $39.39 \%$ and $24 \%$ than jute and banana fibers reinforced epoxy composite.
Prasad Vishnu et. al. [45] developed the natural fiber reinforced composite comprised of jute and banana fiber reinforced to hybrid resin (general resin and cashew nut shell resin) with hand lay-up technique. Tensile testing and FEA analysis (ANSYS) has been done on the composite. Fibres with volume fraction of $10 \%$ to $40 \%$ were reinforced to hybrid resin. More load was carried by alkali treated banana and jute fiber reinforced composite as compare to untreated with same CNSL \% (cashew nut shell resin) i.e. maximum load that a composite withstand was, $1400 \mathrm{~N}$ for jute and $3250 \mathrm{~N}$ for banana with $5 \%$ and $0 \%$ CNSL respectively when treated fibers are used. With increase in volume fraction, maximum load bearing capacity also increases i.e. $1750 \mathrm{~N}$ for jute fibers and $3000 \mathrm{~N}$ for banana fibers with $40 \%$ volume fraction of fibers at 5\% CNSL. DOE using Taguchi method has been used to find number of analysis. L9 orthogonal array and Minitab software is used for regression equation. The contour plot also revealed that with lowest value of CNSL \% when used with $40 \%$ volume fraction has highest load carrying capacity for jute and banana fiber reinforced composites.

Santhanam V. and Chandrasekaran M. [46] reinforced the chopped glass and banana fibers in epoxy matrix to make a hybrid composite. Samples were made with composition of $20 \%$ volume of fiber and $80 \%$ of resin in the composite. Alkaline treatment was also done which showed enhancement of mechanical properties of the composites having tensile strength of $56.24 \mathrm{MPa}$ that is more than untreated fibers of banana (47.32 $\mathrm{MPa}$ ) and was near to pure glass fiber. In case of flexural strength the value comes out to be $76.72 \mathrm{MPa}$ whereas untreated have $35.54 \mathrm{MPa}$ and the water absorption till saturation point also reduced with treatment of fibers.

Tholkappiyan E et. al. [47] investigated the bio composite made from reinforcement of banana fiber into paper pulp. Various parameters like volume fraction of fibres, fiber length and thickness of composite that effect the properties of the composite. Acoustic performance was predicted by the regression model using the Box and Behnken design. Correlation coefficient between the values of observation and prediction comes out to be 0.95. The reduction coefficient of noise through experiment was 0.55 between the $250 \mathrm{~Hz}$ and $4000 \mathrm{~Hz}$ frequency in density of $154 \mathrm{~kg} / \mathrm{m}^{3}$. Fibers having length of $1.5 \mathrm{~cm}$ and $3.5 \mathrm{~cm}$ with thickness of 2 and $6 \mathrm{~cm}$ at 0.20 volume fraction gave minimum and maximum value of NRC. It has been concluded that for the better acoustic performance $20 \%$ volume of fiber at thickness of $6 \mathrm{~cm}$ and having length of 2.5 and $3.5 \mathrm{~cm}$ is optimum.

Bhoopathi R. et. al. [48] fabricated the hybrid composite made from reinforcement of banana-glass-hemp in epoxy resin with the help of hand lay-up method. Mechanical properties were evaluated using UTM which showed that BGFRC had superior properties i.e. $39.5 \mathrm{MPa}$ as compare to 37.5 MPa of HGFRC in terms of tensile strength and flexural strength was very close i.e. $0.50 \mathrm{kN}$ and impact 
strength fall within $5.33 \mathrm{~J}$ to $8.66 \mathrm{~J}$. SEM has been used to look after the internal structures, interracial bond and fractured surface.

Chauhan Sunita and Sharma A. K. [49] explored the various improved techniques of extracting the fiber from the banana stem and trunk with the help of pectinase enzyme through Raspador machine that increases the quality of fiber extracted. 36 hours of incubation results into best quality fibers extracted from the banana stem. It also results into profitable work due to the cheap price of the machine than hand-extracted process to make a good quality paper. With this process, there has been generated a great opportunity for the people of rural areas to increase their economic level and also reduces the solid waste utilization that has been generated from the banana farming.

Ezema Ikechukwu Christian et. al. [50] studied the effect of $\mathrm{NaOH}(4 \%)$ and Na2SO3 (2\%) treated banana stem fiber to make unidirectional natural rubber lamina composites with the help of compression moulding technique. Composite was tested with mass fiber fraction of $30 \%$ and direction of $0^{\circ}, 45^{\circ}$ and $90^{\circ}$. Tensile strength comes out to be $4.03 \mathrm{Mpa}$ where as for untreated it was $3.12 \mathrm{MPa}$ and elastic modulus comes out to be $147.34 \mathrm{MPa}$ where as for untreated it was 84.30 $\mathrm{MPa}$. In terms of orientation of fiber, $0^{\circ}$ gave best results as compare to $45^{\circ}$ and $90^{\circ}$. SEM showed good interface bonding between fiber and matrix when fibers were treated.

Asaithambi B. et.al. [51] fabricated the hybrid composite (sheet) comprised of $30 \%$ by weight banana stem fiber (treated and untreated) reinforcement in the PLA by twin screw extrusion before injection moulding. Due to the wettability and the bonding, banana stem fiber restricts the PLA matrix motion. Tensile strength of virgin PLA was 45 $\mathrm{MPa}$ where as for untreated and treated is 57 and $79 \mathrm{MPa}$ respectively. Similarly flexural strength for pure PLA was $79 \mathrm{MPa}$ and for untreated and treated 91 and $125 \mathrm{MPa}$ respectively. And in case of impact values comes out to be 45, 31.5 and $47.8 \mathrm{~kJ} / \mathrm{m}^{2}$ for composite comprised of virgin PLA, untreated and treated fibers respectively.

Rashid Mamunur et. al. [52] fabricated the two types of MDF (medium density fiberboard) comprised of Musa sapientum (banana plant) i.e. mid rib of banana leaf and banana stem. Mechanical properties were calculated and compared with the market available MDF. Market MDF density was $0.72 \mathrm{~g} / \mathrm{cm}^{3}$, MOR $40.65 \mathrm{~N} / \mathrm{mm}^{2}$ and MOE $3518.63 \mathrm{~N} / \mathrm{mm}^{2}$. Whereas for banana stem MDF and mid rib MDF values were $0.78 \mathrm{~g} / \mathrm{cm}^{3}, 50.91 \mathrm{~N} / \mathrm{mm}^{2}, 3939.25$ $\mathrm{N} / \mathrm{mm}^{2}$ and $0.74 \mathrm{~g} / \mathrm{cm} 3,45.30 \mathrm{~N} / \mathrm{mm}^{2}, 3518.63 \mathrm{~N} / \mathrm{mm}^{2}$ respectively for density, MOR and MOE which showed good potential of the fabricated MDF in the market and banana stem and mid rib could be a good option for MDF industries.

\section{GAP IN RESEARCH}

Till date many researchers did work on the making of composite rods but only with the help of pultrusion process. But for pultrusion process we need fibers in yarn form so that they can be pultruded after dipping in the resin. In other context researchers used the chopped fibers with PLA but only in injection moulding after mixing the PLA and fibers in twin screw extruder for making of sheets. Nothing has been done till date for the extrusion of rods from the PLA and chopped fibers with help of extrusion process. So with this one can able to fabricate any product with the help of extrusion by chopping any type of plant or animal fibers which can't be easily converted into fine yarns.

\section{CONCLUSION}

This review paper explains different methods of manufacturing composites using Banana fibers with any matrix either biodegradable or non-biodegradable. Different techniques to process these fibers to get best properties out of them are explained efficiently by different researchers. Some constraints and deficiencies also exist in several methods but with some additions or modifications good results have been obtained which paved way for the researchers to carry out their research work in banana fibers reinforcements in available matrix. PLA having good properties and biodegradable nature becomes very good option to call upon for making fully biodegradable composites.

\section{ACKNOWLEDGEMENT}

I would like to express my sincere gratitude to IKG PTU Kapurthala to allow me in collecting relevant information in terms of review paper to find the problem for my research work of $\mathrm{PhD}$. My sincere thanks also goes to my guides Dr.Sehijpal Singh and Dr. Vikas Dhawan for their continuous support in writing this review paper and collecting required literature related to my $\mathrm{PhD}$ research work, with complete patience, motivation, and their immense knowledge.

\section{REFERENCES}

[1] Avérous, Luc. "Biodegradable multiphase systems based on plasticized starch: a review." Journal of Macromolecular Science, Part C: Polymer Reviews ,Vol 44, pp: 231-274, 2004.

[2] Frazza, E. J., and E. E. Schmitt. "A new absorbable suture." Journal of biomedical materials research, Vol 5, pp: 43-58, 1971.

[3] Gilding, D. K., and A. M. Reed. "Biodegradable polymers for use in surgery—polyglycolic/poly (actic acid) homo-and copolymers: 1." Polymer, Vol 20, pp: 1459-1464, 1979.

[4] Ratner, Buddy D., Allan S. Hoffman, Frederick J. Schoen, and Jack E. Lemons. Biomaterials science: an introduction to materials in medicine. Elsevier, 2004.

[5] Vert, M., S. M. Li, G. Spenlehauer, and Ph Guérin. "Bioresorbability and biocompatibility of aliphatic polyesters." Journal of materials science: Materials in medicine, Vol 3, pp: 432-446, 1992.

[6] Engelberg, Israel, and Joachim Kohn. "Physico-mechanical properties of degradable polymers used in medical applications: a comparative study." Biomaterials, Vol 12, pp: 292-304, 1991. 
[7] www.plasticstechnology.com/articles/200203fa2.html (accessed August 2004).

[8] Jamshidi, K., S-H. Hyon, and Y. Ikada. "Thermal characterization of polylactides." Polymer, Vol 29, pp: 2229-2234, 1988.

[9] Dorgan, John R., Hans Lehermeier, and Michael Mang. "Thermal and rheological properties of commercial-grade poly (lactic acid) s." Journal of Polymers and the Environment, Vol 8, pp: 1-9, 2000.

[10] Datta, Rathin, and Michael Henry. "Lactic acid: recent advances in products, processes and technologies—a review." Journal of Chemical Technology \& Biotechnology: International Research in Process, Environmental \& Clean Technology, Vol 81, pp: 1119-1129, 2006.

[11] Mehta, Rajeev, Vineet Kumar, Haripada Bhunia, and S. N. Upadhyay. "Synthesis of poly (lactic acid): a review." Journal of Macromolecular Science, Part C: Polymer Reviews, Vol 45, pp: 325349, 2005.

[12] Patel, Martin, F. Marscheider-Weidemann, J. Schleich, B. Hüsing, and G. Angerer. "Techno-economic feasibility of large-scale production of bio-based polymers in Europe." Techncial Report EUR 22103, 2005.

[13] Lim, Jung Yul, Soo Hyun Kim, Soonho Lim, and Young Ha Kim. "Improvement of Flexural Strengths of Poly (L-lactic acid) by Solid-State Extrusion, 2. Extrusion through Rectangular Die." Macromolecular Materials and Engineering ,Vol 288, pp: 5057, 2003.

[14] Furukawa, Tsuyoshi, Harumi Sato, Rumi Murakami, Jianming Zhang, Yong-Xin Duan, Isao Noda, Shukichi Ochiai, and Yukihiro Ozaki. "Structure, dispersibility, and crystallinity of poly (hydroxybutyrate)/poly (L-lactic acid) blends studied by FT-IR microspectroscopy and differential scanning calorimetry." Macromolecules, Vol 38, pp: 6445-6454, 2005.

[15] Mills, Christopher A., Melba Navarro, Elisabeth Engel, Elena Martinez, Maria Pau Ginebra, Josep Planell, Abdelhamid Errachid, and Josep Samitier. "Transparent micro-and nanopatterned poly (lactic acid) for biomedical applications." Journal of Biomedical Materials Research Part A: An Official Journal of The Society for Biomaterials, The Japanese Society for Biomaterials, and The Australian Society for Biomaterials and the Korean Society for Biomaterials, Vol 76, pp: 781-787, 2006.

[16] Mohanty, Amar Kumar, Manjusri Misra, and L. T. Drzal. "Sustainable bio-composites from renewable resources: opportunities and challenges in the green materials world." Journal of Polymers and the Environment, Vol 10, pp: 19-26, 2002.

[17] Mohanty, A. K., Manjusri Misra, and Lawrence T. Drzal. "Surface modifications of natural fibers and performance of the resulting biocomposites: an overview." Composite interfaces, Vol 8, pp: 313343, 2001.

[18] Alvarez, Vera A., Roxana A. Ruscekaite, and Analia Vazquez. "Mechanical properties and water absorption behavior of composites made from a biodegradable matrix and alkaline-treated sisal fibers." Journal of composite materials, Vol 37, pp: 1575-1588, 2003.

[19] Frederick, T. W., and W. Norman. "Natural fibers plastics and composites." EUA: Kluwer Academic Publishers, 2004.

[20] Mohanty, A. K., Manjusri Misra, and Lawrence T. Drzal. "Surface modifications of natural fibers and performance of the resulting biocomposites: an overview." Composite interfaces, Vol 8, pp: 313343, 2001.

[21] Valadez-Gonzalez, A., J. M. Cervantes-Uc, R. J. I. P. Olayo, and P. J. Herrera-Franco. "Effect of fiber surface treatment on the fiber-matrix bond strength of natural fiber reinforced composites." Composites Part B: Engineering, Vol 30, pp: 309-320, 1999.

[22] Agrawal, Richa, N. S. Saxena, K. B. Sharma, S. Thomas, and M. S. Sreekala. "Activation energy and crystallization kinetics of untreated and treated oil palm fibre reinforced phenol formaldehyde composites." Materials Science and Engineering: A, Vol 277, pp: 7782, 2000.

[23] Valadez-Gonzalez, A., J. M. Cervantes-Uc, R. Olayo, and P. J. Herrera-Franco. "Chemical modification of henequen fibers with an organosilane coupling agent." Composites Part B: Engineering, Vol 30, pp: 321-331, 1999.

[24] Hill, Callum AS, HPS Abdul Khalil, and Mike D. Hale. "A study of the potential of acetylation to improve the properties of plant fibres." Industrial Crops and Products, Vol 8, pp: 53-63, 1998.
[25] Paul, Satya, Puja Nanda, and Rajive Gupta. "PhCOCl-Py/basic alumina as a versatile reagent for benzoylation in solvent-free conditions." Molecules ,Vol 8, pp: 374-380, 2003.

[26] Chokshi, Rina, and Hossein Zia. "Hot-melt extrusion technique: a review." Iranian Journal of Pharmaceutical Research, Vol 3, pp: 316, 2010.

[27] Whelan, Tony, and David Dunning. The Dynisco Extrusion Processors Handbook. Dynisco Incorporated, 1988.

[28] [28] Breitenbach, Jörg. "Melt extrusion: from process to drug delivery technology." European Journal of Pharmaceutics and Biopharmaceutics, Vol 54, pp: 107-117, 2002.

[29] Andrews, Gavin P., David S. Jones, O. Abu Diak, Daniel N. Margetson, and M. S. McAllister. "Hot-melt extrusion: an emerging drug delivery technology." Pharmaceutical Technology Europe, Vol 21, pp: 24-27, 2009.

[30] Santhosh, J., N. Balanarasimman, R. Chandrasekar, and S. Raja. "Study of properties of banana fiber reinforced composites." International Journal of Research in Engineering and Technology, Vol 3, pp: 144-150, 2014.

[31] Madhukiran. J, Dr. S. Srinivasa Rao and Madhusudan. S, "Tensile And Hardness Properties Of Banana/Pineapple Natural Fibre Reinforced Hybrid Composites", International Journal of Engineering Research \& Technology, Vol. 2, pp: 1260-1264, 2013.

[32] Shih, Yeng-Fong, and Chien-Chung Huang. "Polylactic acid (PLA)/banana fiber (BF) biodegradable green composites." Journal of polymer Research, Vol 18, pp: 2335-2340, 2011.

[33] Jandas, P. J., S. Mohanty, S. K. Nayak, and H. Srivastava. "Effect of surface treatments of banana fiber on mechanical, thermal, and biodegradability properties of PLA/banana fiber biocomposites." Polymer Composites, Vol 32, pp: 1689-1700, 2011.

[34] Paul, Sherely Annie, Abderrahim Boudenne, Laurent Ibos, Yves Candau, Kuruvilla Joseph, and Sabu Thomas. "Effect of fiber loading and chemical treatments on thermophysical properties of banana fiber/polypropylene commingled composite materials." Composites Part A: Applied Science and Manufacturing, Vol 39, pp: 1582-1588, 2008.

[35] Ranjan, Ravi, P. K. Bajpai, and R. K. Tyagi. "Mechanical characterization of banana/sisal fibre reinforced PLA hybrid composites for structural application.” Engineering International, Vol 1, pp: 39-48, 2013.

[36] Kumar, Rakesh, Veena Choudhary, Saroj Mishra, and I. K. Varma. "Banana fiber-reinforced biodegradable soy protein composites." Frontiers of Chemistry in China, Vol 3, pp: 243-250, 2008.

[37] Deepa, B., Eldho Abraham, Bibin Mathew Cherian, Alexander Bismarck, Jonny J. Blaker, Laly A. Pothan, Alcides Lopes Leao, Sivoney Ferreira De Souza, and M. Kottaisamy. "Structure, morphology and thermal characteristics of banana nano fibers obtained by steam explosion." Bioresource Technology, Vol 102, pp: 1988-1997, 2011.

[38] Idicula, Maries, N. R. Neelakantan, Zachariah Oommen, Kuruvilla Joseph, and Sabu Thomas. "A study of the mechanical properties of randomly oriented short banana and sisal hybrid fiber reinforced polyester composites." Journal of applied polymer science, Vol 96, pp: 1699-1709, 2005.

[39] Thiruchitrambalam, M., A. Alavudeen, A. Athijayamani, N. Venkateshwaran, and A. Elaya Perumal. "Improving mechanical properties of banana/kenaf polyester hybrid composites using sodium laulryl sulfate treatment." Materials physics and Mechanics, Vol 8, pp: 165-173, 2009.

[40] Sajna, V. P., Smita Mohanty, and Sanjay K. Nayak. "Hybrid green nanocomposites of poly (lactic acid) reinforced with banana fibre and nanoclay." Journal of Reinforced Plastics and Composites, Vol 33, pp: 1717-1732, 2014.

[41] Ghosh, Rajesh, A. Ramakrishna, G. Reena, A. Ravindra, and Abhishek Verma. "Water absorption kinetics and mechanical properties of ultrasonic treated banana fiber reinforced-vinyl ester composites." Procedia Materials Science, Vol 5, pp: 311-315, 2014.

[42] Deka Binapani, Deka Pankaj and Borgohain Rupam, "Exploration of banana fibre as low cost eco-friendly waste management." Asian Journal of Bio Science, Vol 9, pp: 129-130, 2014.

[43] Santhanam, V., M. Chandrasekaran, N. Venkateshwaran, and A. Elayaperumal. "Mode I fracture toughness of banana fiber and glass 
fiber reinforced composites." In Advanced Materials Research, Vol. 622, pp: 1320-1324, 2013.

[44] Khalifa Mohammed and Bagawan Altaf Hussain, "Experimental Investigation of Effect of Fibre Diameter on Tensile Properties of Jute - Banana Fibre (Hybrid) Reinforced Epoxy Composite", International Journal of Engineering Research \& Technology (IJERT), Vol. 3, pp: 1799-1807, 2014.

[45] Prasad, Vishnu, Ajil Joy, G. Venkatachalam, S. Narayanan, and S. Rajakumar. "Finite Element analysis of jute and banana fibre reinforced hybrid polymer matrix composite and optimization of design parameters using ANOVA technique." Procedia Engineering, Vol 97, pp: 1116-1125, 2014.

[46] Santhanam, V., and M. Chandrasekaran. "Effect of Surface Treatment on the Mechanical Properties of Banana-Glass Fibre Hybrid Composites." In Applied Mechanics and Materials, Vol. 591, pp: 710, 2014

[47] Tholkappiyan, E., Dhandapani Saravanan, R. Jagasthitha, T. Angeswari, and V. T. Surya. "Prediction of acoustic performance of banana fiber-reinforced recycled paper pulp composites." Journal of Industrial textiles, Vol 45, pp: 1350-1363, 2016.
[48] Bhoopathi, R., M. Ramesh, and C. Deepa. "Fabrication and property evaluation of banana-hemp-glass fiber reinforced composites." procedia engineering, Vol 97, pp: 2032-2041, 2014.

[49] Chauhan Sunita and Sharma AK, "Utilization of Pectinases for Fiber Extraction from Banana Plant's Waste”, International Journal of Waste Resources, Vol 4, pp: 1-6, 2014.

[50] Ezema, Ikechukwu Christian, AR Ravindranatha Menon, Camelus Sunday Obayi, and Augustin Dinobi Omah. "Effect of surface treatment and fiber orientation on the tensile and morphological properties of banana stem fiber reinforced natural rubber composite." Journal of Minerals and Materials Characterization and Engineering, Vol 2, pp: 216-222, 2014.

[51] Asaithambi, B., G. Ganesan, and S. Ananda Kumar. "Bio-composites: Development and mechanical characterization of banana/sisal fibre reinforced poly lactic acid (PLA) hybrid composites." Fibers and Polymers, Vol 15, pp: 847-854, 2014.

[52] Rashid, Md Mamunur, Atanu Kumar Das, Md Iftekhar Shams, and Subir Kumar Biswas. "Physical and mechanical properties of medium density fiber board (MDF) fabricated from banana plant (Musa sapientum) stem and midrib." Journal of the Indian Academy of Wood Science, Vol 11, pp: 1-4, 2014. 